\title{
TOlerÂnCIA de Espécies de MuCuna a HeRbicidas Utilizados Na Cultura da Cana-De-AçÚCAR ${ }^{1}$
}

\author{
Tolerance of Mucuna Species to Herbicides used in Sugarcane Culture \\ SILVA, G.B.F. ${ }^{2}$, AZANIA, C.A.M. ${ }^{3}$, NOVO, M.C.S.S. ${ }^{4}$, WUTKE, E.B. ${ }^{5}$, ZERA, F.S. ${ }^{6}$ e \\ AZANIA, A.A.P.M. ${ }^{7}$
}

\begin{abstract}
RESUMO - Os fluxos de emergência de Mucuna em canaviais, mesmo após a aplicação dos herbicidas para o manejo de plantas daninhas, permitiu elaborar a hipótese de que essas plantas são tolerantes aos herbicidas comumente utilizados na cultura. Para comprovar a hipótese, objetivou-se estudar a tolerância de Mucuna aterrima, Mucuna cinerea e Mucuna deeringiana a herbicidas de diferentes mecanismos de ação aplicados em pré e pós-emergência. O delineamento experimental utilizado foi o de blocos casualizados com nove tratamentos, em cinco repetições, dispostos em esquema fatorial $3 \times 3$, mais testemunhas. $\mathrm{Na}$ pré-emergência, o primeiro fator foi constituído pelos herbicidas sulfentrazone $\left(800 \mathrm{~g} \mathrm{ha}^{-1}\right)$, imazapic $\left(245 \mathrm{~g} \mathrm{ha}^{-1}\right)$ e amicarbazone $\left(1.400 \mathrm{~g} \mathrm{ha}^{-1}\right)$, e o segundo, pelas três espécies de Mucuna, além de uma testemunha para cada espécie estudada. Na pós-emergência, alteraram-se os herbicidas para clomazone $\left(1.100 \mathrm{~g} \mathrm{ha}^{-1}\right)$, ametryn+trifloxysulfuron-sodium $\left(1.463+37 \mathrm{~g} \mathrm{ha}^{-1}\right)$ e 2,4-D (1.209 $\left.\mathrm{g} \mathrm{ha}^{-1}\right)$. No manejo químico em pré-emergência, verificou-se que as espécies foram sensiveis ao herbicida amicarbazone, seguido de sulfentrazone, e tolerantes ao imazapic. $\mathrm{Na}$ pós-emergência, todas as espécies foram sensiveis ao ametryn+trifloxysulfuron-sodium e 2,4-D, mas tolerantes ao clomazone.
\end{abstract}

Palavras-chave: controle, Mucuna aterrima, Мucuna cinerea, Mucuna deeringiana.

\begin{abstract}
The emergence of Mucuna species in sugarcane plantations, even after herbicide spraying for weed management, allowed us to elaborate the hypothesis that these plants are tolerant to the herbicides commonly used in the culture. Thus, to prove this hypothesis, this work was carried out to study the tolerance of Mucuna aterrima, Mucuna cinerea and Mucuna deeringiana to application of herbicides with different mechanisms of action in pre- and postemergence. The experiment was arranged in a randomized block design with 9 treatments and five replications in a factorial $3 \times 3$, plus controls. At pre-emergence, the first factor was constituted by the herbicides sulfentrazone (800 $\left.\mathrm{g} \mathrm{ha}^{-1}\right)$, imazapic (245 $\left.\mathrm{g} \mathrm{ha}^{-1}\right)$, and amicarbazone $(1,400 \mathrm{~g} \mathrm{ha}-1)$, and the second factor by the Mucuna species, besides the additional control for each species studied. At post-emergence, the herbicides tested were clomazone $\left(1,100 \mathrm{~g} \mathrm{ha}^{-1}\right)$, ametryn+trifloxysulfuronsodium (1, $\left.463+37 \mathrm{~g} \mathrm{ha}^{-1}\right)$, and 2, 4-D (1,209 $\left.\mathrm{g} \mathrm{ha}^{-1}\right)$. In the chemical management at pre-emergence, the species were sensitive to amicarbazone, followed by sulfentrazone, and tolerant to imazapic. At post-emergence, all species were sensitive to ametryn + trifloxysulfuron-sodium and 2,4-D, but tolerant to clomazone.
\end{abstract}

Keywords: control, Mucuna aterrima, Mucuna cinerea, Mucuna deeringiana.

Recebido para publicação em 13.6.2011 e aprovado em 15.6.2012.

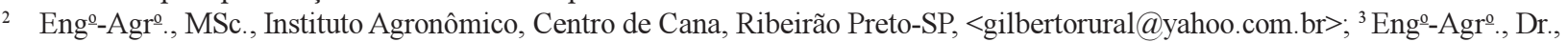
PqC, Inst. Agronômico, Centro de Cana, Rodov. Pref. Antonio Duarte Nogueira, Km 321, 14032-800 Ribeirão Preto-SP, <azania@iac.sp.gov.br>; ${ }^{4}$ Eng $^{\mathrm{a}}-\mathrm{Agr}{ }^{\mathrm{a}}$., Dra., PqC, Inst. Agronômico, Centro de Ecofisologia e Biofísica, Avenida Theodureto de Almeida Camargo, 1500, Caixa Postal 28, 13001-970 Campinas-SP, <mcdesalvo@hotmail.com>; ${ }^{5}$ Eng - -Agr ${ }^{\mathrm{a}}$., Dra., PqC., Inst. Agronômico, Centro de Grãos e Fibras, 13075-630 Campinas-SP, <ebwutke@iac.sp.gov.br>; ${ }^{6}$ Engo-Agro ${ }^{\circ}$, Doutorando em Agronomia, Faculdade de Ciências Agrárias e Veterinárias, Jaboticabal, Via de Acesso Prof. Paulo Donato Castellane s/n, 14884-900 Jaboticabal-SP, $<$ fabricio0_sp@hotmail.com>; 7 Bióloga, Pós-Doutoranda, Inst. Agronômico, Centro de Cana, Ribeirão Preto-SP, <andrea.azania@hotmail.com>. 


\section{INTRODUÇÃO}

A mucuna (Mucuna spp.) pertence à família Fabaceae. Por ser de crescimento rápido e possuir grande quantidade de massa verde para cobertura do solo, é muito utilizada na agricultura brasileira como planta de cobertura (Sakai et al., 2007), agregando ao solo melhorias físicas e químicas (Junior \& Coelho, 2008), além de possibilitar a supressão de plantas daninhas (Fernandes et al., 1999; Favero et al., 2001).

A maioria das espécies do gênero Mucuna é indicada para a prática da adubação verde. A mucuna-preta (Mucuna aterrima) é uma planta de hábito de crescimento trepador e, de acordo com Souza \& Yamashita (2006), utilizada devido ao volume de massa verde produzida em curto espaço de tempo; entretanto, em razão dessa característica, pode ocupar rapidamente áreas, provocando competição por água, luz e nutrientes, tornando-se uma planta que pode provocar interferências na produção. A mucuna-cinza (Mucuna cinereum) também é de hábito de crescimento trepador, enquanto a mucuna-anã (Mucuna deeringiana) tem crescimento determinado. Ambas podem evitar a multiplicação de nematoides fitoparasitas, que causam grandes danos às culturas (Sakai et al., 2007).

Quando o manejo das plantas de Mucuna spp. é inadequado - a ponto de impossibilitar a incorporação dessas plantas no momento certo -, elas são incorporadas tardiamente ao solo. Segundo Correia (2011), ocorre o aumento da quantidade de sementes no solo, as quais apresentam dormência e germinação escalonada, como as de uma planta daninha verdadeira. Assim, passam a ser infestantes, constituindo-se em um problema. A dureza do tegumento, que também proporciona dormência às sementes de mucuna e pode estar presente entre 60 e $80 \%$ dos propágulos, é a principal responsável pelos diferentes fluxos de emergência de plântulas ao longo dos anos (Maeda \& Lago, 1986).

$\mathrm{Na}$ literatura nacional, os estudos referentes a manejo químico de adubos verdes são recentes, a exemplo do trabalho de Oliveira Neto et al. (2011), que estudaram as misturas em tanque de glyphosate + 2,4-D + carfentrazone-ethyl e glyphosate $+2,4-D$ no manejo de Mucuna aterrima e Crotalaria spectabilis. Também Correia (2011) avaliou a eficácia do herbicida mesotrione, aplicado isolado e em mistura, para o controle em pósemergência de mucuna-preta e corda-de-viola em área de cana-soca colhida mecanicamente sem queima da palha.

Por constatar infestações elevadas de Mucuna spp. nos canaviais, mesmo após a utilização dos herbicidas como principal forma de manejo de plantas daninhas, pôde-se formular a hipótese de que as espécies possam ser tolerantes aos herbicidas comumente empregados na cultura. Para constatar essa afirmação, objetivou-se estudar a tolerância de $M$. aterrima, $M$. cinerea e $M$. deeringiana a herbicidas de diferentes mecanismos de ação, aplicados em pré e pós-emergência.

\section{MATERIAL E MÉTODOS}

O experimento foi instalado em campo, de novembro/09 a janeiro/10, na condição de pré e pós-emergência das espécies de Mucuna. O solo foi classificado como Latossolo Vermelho eutroférrico de textura argiloarenosa $(41,7 \%$ de argila, $51,3 \%$ de areia e $6,8 \%$ de silte). A análise físico-química de amostras desse solo na profundidade de $20 \mathrm{~cm}$ revelou 5,8 de $\mathrm{pH}$; $34 \mathrm{~g} \mathrm{dm}^{-3}$ de matéria orgânica; $40 \mathrm{mg} \mathrm{dm}^{-3} \mathrm{de}$ $\mathrm{P}_{\text {(resina) }} ; 7,4 \mathrm{mmol}_{\mathrm{c}} \mathrm{dm}^{-3} \mathrm{de} \mathrm{K} ; 47 \mathrm{mmol}_{\mathrm{c}} \mathrm{dm}^{-3} \mathrm{de}$ Ca; 17 mmol $_{c} \mathrm{dm}^{-3}$ de $\mathrm{Mg}$; 99,2 $\mathrm{mmol}_{\mathrm{c}} \mathrm{dm}^{-3} \mathrm{de}$ capacidade de troca catiônica (CTC); $72 \%$ de V\%; $41,7 \%$ de argila; $51,3 \%$ de areia; e $6,8 \%$ de silte. Na safra 2008/2009, anterior à instalação do experimento, a área havia sido cultivada com girassol em manejo orgânico, sem aplicação de qualquer defensivo agrícola e adubação química.

Para cada condição de aplicação (pré e pósemergência) utilizou-se o delineamento em blocos casualizados com nove tratamentos e cinco repetições, analisado em esquema fatorial $3 \times 3$, mais testemunha. O primeiro fator foi constituído pelos herbicidas aplicados em pré-emergência (sulfentrazone $800 \mathrm{~g} \mathrm{ha}^{-1}$; imazapic - $245 \mathrm{~g} \mathrm{ha}^{-1}$; amicarbazone - $1.400 \mathrm{~g} \mathrm{ha}^{-1}$ ) e em pós-emergência (clomazone - $1.100 \mathrm{~g} \mathrm{ha}^{-1}$; ametryn+ trifloxysulfuron-sodiun $-1.463+37 \mathrm{~g} \mathrm{ha}^{-1} ; 2,4-\mathrm{D}$ - $\left.1.209 \mathrm{~g} \mathrm{ha}^{-1}\right)$, e o segundo, pelas espécies de Mucuna (Mucuna aterrima, Mucuna cinerea e 
Mucuna deeringiana), acrescidos de testemunha adicional para cada espécie estudada. Em ambos os ensaios, as parcelas foram constituídas por cinco linhas com $5 \mathrm{~m}$ de comprimento, espaçadas de $0,5 \mathrm{~m}$, sendo a área útil da parcela constituída pelas três linhas centrais, totalizando uma área útil de $7,5 \mathrm{~m}^{2}$.

As sementes de $M$. aterrima e $M$. cinerea, devido à dormência natural (Wutke et al., 1995), foram submetidas à superação da dormência. Elas foram acondicionadas em sacos de fibra vegetal e imersas em água quente a $70{ }^{\circ} \mathrm{C}$ por 10 segundos; após escorrer o excesso de água, foram colocadas para secagem em local ventilado e à sombra, conforme adaptado de Trani et al. (1991). M. deeringiana não apresenta dormência em suas sementes e não foi submetida ao procedimento. Após o prévio tratamento de superação de dormência, as sementes foram utilizadas no teste de germinação e viabilidade.

Para o teste de germinação, utilizaramse 200 sementes de cada espécie, distribuídas em quatro repetições. As sementes foram dispostas em bandejas de plástico de 29,5 x 40 x $7 \mathrm{~cm}$, preenchidas com areia previamente lavada e esterilizada em autoclave. Após a semeadura, as sementes foram cobertas com $1 \mathrm{~cm}$ de areia e mantidas em casa de vegetação por 25 dias, com irrigação diária em quantidade suficiente para manter o substrato úmido, a fim de que as sementes entrassem em processo de germinação. Diariamente, contou-se o número de plantas emergidas até o 25을 dia, sendo consideradas apenas as plântulas com as duas folhas cotiledonares abertas como germinadas; no final, calculouse a porcentagem de emergência (("número de plântulas emergidas até o 25을a/número de sementes semeadas")*100).

O teste de viabilidade foi realizado utilizando-se das sementes não germinadas do teste de germinação. As sementes foram recuperadas pela lavagem do substrato com água e auxilio de peneira (malha de 0,5 mesh), cortadas longitudinalmente e colocadas em copos plásticos de $25 \mathrm{~mL}$, preenchidos com solução de cloreto de 2,3,5 trifeniltetrazólio a $0,1 \%$. Os recipientes foram cobertos com tecido preto para proteção da luz - evitando-se reação fotoquímica com a solução utilizada - e mantidos durante oito horas em temperatura ambiente $\left(27^{\circ} \mathrm{C}\right)$. Posteriormente, realizou-se a contagem do número de sementes com embriões coloridos de rosa (sementes viáveis) e brancos ou cinza (sementes mortas) e calculou-se a viabilidade (l("número de sementes viáveis/número de sementes semeadas) *100)+ " \% de emergência obtida).

No final, o lote de sementes de $M$. aterrima apresentou 59 e 98\%, $M$. cinerea, 98 e 100\%, e M. deeringiana, 57 e 58\%, para porcentagem de emergência de plantas e porcentagem de viabilidade, respectivamente.

Em 4/11/2009, o solo foi preparado com grade leve e sulcado a $15 \mathrm{~cm}$ de profundidade. A semeadura foi realizada no dia posterior, ocasião em que se realizou a adequação da fertilidade do solo à cultura da cana-de-açúcar, para simular as mesmas condições nutricionais que as infestantes encontrariam nos canaviais. No sulco de semeadura foi aplicado o correspondente a $30 \mathrm{~kg} \mathrm{ha}^{-1}$ de $\mathrm{N} \mathrm{e} 80 \mathrm{~kg}^{-1}$ de $\mathrm{P}_{2} \mathrm{O}_{5}$, não sendo necessário corrigir os niveis de potássio em função dos resultados da análise química. A semeadura foi realizada manualmente em 5/11/2009 nos experimentos em pré e pós-emergência, depositando-se quatro sementes por metro linear, correspondente a 20 plantas de mucuna por linha.

A aplicação dos herbicidas, em ambas as condições, foi feita com pulverizador costal pressurizado a $\mathrm{CO}_{2}$, munido de barra com quatro pontas de jato tipo leque (TT 110.02), espaçadas de $0,50 \mathrm{~m}$, o qual, regulado com pressão constante de $2,1 \mathrm{kgf} \mathrm{cm}^{-2}$, proporcionou volume de calda correspondente a $250 \mathrm{~L} \mathrm{ha}^{-1}$.

Em pré-emergência, os herbicidas foram aplicados após a semeadura das plantas daninhas, com início às $6 \mathrm{~h} 30$ e término às $8 \mathrm{~h} 10$, registrando-se temperatura do ar de $23,1{ }^{\circ} \mathrm{C}$, umidade relativa de $83 \%$, vento em rajadas de $1,6 \mathrm{~km} \mathrm{~h}^{-1}$ e nebulosidade de 95\%. Para a condição de pós-emergência, os herbicidas foram aplicados em $27 / 11 / 2009$, quando as plantas de Mucuna spp. estavam com altura média de $20 \mathrm{~cm}$ e sete trifólios. A aplicação teve início às $8 \mathrm{~h} 30$ e término às $10 \mathrm{~h} 10$, registrando-se temperatura do ar de $32,9{ }^{\circ} \mathrm{C}$, umidade relativa de $54,6 \%$, vento em rajadas de $2,0 \mathrm{~km} \mathrm{~h}^{-1}$ e nebulosidade de $90 \%$. 
A escolha das dosagens dos herbicidas foi realizada de acordo com a máxima permitida pelo Ministério da Agricultura, Pecuária e Abastecimento (MAPA) à cultura da cana-deaçúcar. Após a aplicação dos herbicidas foram realizadas capinas, deixando o experimento sempre na ausência de plantas daninhas, evitando competição entre as plantas de Mucuna spp. e a flora infestante.

Em ambos os experimentos avaliou-se o percentual de intoxicação, observado visualmente na parte aérea das plantas, para a condição de pré-emergência aos 30 e 45 dias após aplicação (DAA) e para pós-emergência aos 10 e 30 DAA. Para o percentual de intoxicação foi atribuído $0 \%$ à ausência de injúrias e $100 \%$ à morte das plantas. Aos 45 DAA, para a condição de pré-emergência, e 30 DAA, para a condição de pós-emergência, foram avaliados nas três linhas centrais de cada parcela o comprimento de plantas $(\mathrm{cm})$, medindo-se todas as plantas do nível do solo até a última folha; o número total de plantas, contando-se as plantas de todas as linhas; e a massa seca da parte aérea por espécie, cortando-se todas as plantas rente ao solo, com posterior secagem em estufa de circulação forçada de ar em temperatura de $70{ }^{\circ} \mathrm{C}$ até massa constante.

As variáveis avaliadas foram submetidas à análise de variância pelo teste $\mathrm{F}$, e as médias, comparadas pelo teste de Tukey a 5\% de probabilidade, utilizando-se o programa estatístico computacional ESTAT.

\section{RESULTADOS E DISCUSSÃO}

Nos experimentos em pré e pós-emergência, as plantas da testemunha, independentemente do hábito de crescimento, apresentaram-se vigorosas e com fechamento rápido, suficiente para expressar o potencial de agressividade das espécies quanto à interferência sobre as culturas e à necessidade de controlá-las. Em todas as variáveis estudadas, as plantas das testemunhas diferiram do fatorial proposto (tratamentos herbicidas). $\mathrm{Na}$ pré-emergência, $M$. cinerea apresentou comprimento dos ramos e massa seca superiores aos das demais espécies, pois possui crescimento indeterminado, rápido e vigoroso. $M$. aterrima apresentou valores inferiores aos de $M$. cinerea, mas superiores aos de
$M$. deeringiana, que tem crescimento determinado. Na pós-emergência, M. aterrima apresentou número de plantas, comprimento e massa seca superiores aos das demais espécies (Tabela 1).

Nas plantas tratadas com os herbicidas aplicados em pré-emergência, observou-se, aos 30 DAA (Tabela 2), que a espécie mais sensivel aos tratamentos herbicidas foi $M$. deeringiana, seguida por $M$. cinerea $\mathrm{e}$ $M$. aterrima, que tiveram os sintomas de intoxicação caracterizados por encarquilhamento e manchas necróticas nas folhas, além da redução de porte das plantas. A interação entre herbicidas e espécies aos 30 DAA também elucidou que a intoxicação mais elevada foi causada pelo amicarbazone, principalmente para $M$. cinerea e $M$. deeringiana $(90 \%)$, enquanto para $M$. aterrima foi mais moderada (70\%). O imazapic causou os menores niveis de injúrias, sendo no máximo de $30 \%$ de fitotoxicidade para M. deeringiana. Entretanto, pode-se constatar que $M$. deeringiana foi a espécie mais afetada pelas injúrias causadas pelos herbicidas.

A intoxicação observada nas plantas evoluiu aos 45 DAA; $M$. deeringiana e $M$. cinerea ainda foram as espécies mais prejudicadas, particularmente nas plantas tratadas com amicarbazone e sulfentrazone (Tabela 2).

$\mathrm{O}$ amicarbazone proporcionou intoxicação mais elevada para todas as plantas de Mucuna, mas somente pode ser indicado para o manejo em pré-emergência de $M$. deeringiana e $M$. cinerea, por ter erradicado suas plantas. Entretanto, para $M$. aterrima, a indicação do herbicida é menos segura, por ter proporcionado intoxicação menos intensa. O sulfentrazone proporcionou sintomas com atribuição de notas entre 68 e $76 \%$ - inferiores àquelas proporcionadas pelo amicarbazone. O imazapic somente proporcionou sintomas menos intensos à parte aérea das plantas, sendo as notas atribuídas não superiores a $16 \%$.

Mesmo pertencendo a familias distintas, o comportamento de desenvolvimento entre as espécies de Mucuna é similar ao do das Convolvulaceae, uma vez que $M$. cinerea também possui hábito trepador e tem crescimento indeterminado, assim como $M$. aterrima, que pode atingir de 6 a $8 \mathrm{~m}$. 
Tabela 1 - Porcentagem de intoxicação, número de plantas, comprimento e massa seca das plantas de Mucuna aterrima, Mucuna cinerea e Mucuna deeringiana nas parcelas testemunhas nos ensaios de pré e pós-emergência

\begin{tabular}{|c|c|c|c|c|c|c|}
\hline \multirow[b]{2}{*}{ Experimento } & \multirow[b]{2}{*}{ Espécie } & \multirow{2}{*}{$\begin{array}{c}30 \text { DAA } \\
\text { Intoxicação } \\
(\%)\end{array}$} & \multicolumn{4}{|c|}{$45 \mathrm{DAA}$} \\
\hline & & & $\begin{array}{c}\text { Intoxicação } \\
(\%)\end{array}$ & $\begin{array}{l}\text { Plantas } \\
\left(7,5 \mathrm{~m}^{2}\right)\end{array}$ & $\begin{array}{l}\text { Comprimento } \\
\text { planta }(\mathrm{cm})\end{array}$ & 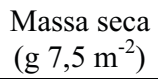 \\
\hline \multirow{5}{*}{ Pré-emergência } & Mucuna aterrima & $\begin{array}{c}5,74 \mathrm{a} \\
(0)\end{array}$ & $\begin{array}{c}5,74 \mathrm{a} \\
(0)\end{array}$ & $\begin{array}{l}35,53 \mathrm{a} \\
(33,40)\end{array}$ & $\begin{array}{l}10,00 \mathrm{ab} \\
(104,54)\end{array}$ & $\begin{array}{l}13,72 \mathrm{ab} \\
(198,80)\end{array}$ \\
\hline & Mucuna cinerea & $\begin{array}{c}5,74 \mathrm{a} \\
(0)\end{array}$ & $\begin{array}{c}5,74 \mathrm{a} \\
(0)\end{array}$ & $\begin{array}{l}36,91 \mathrm{a} \\
(36,40)\end{array}$ & $\begin{array}{c}13,21 \mathrm{a} \\
(179,36)\end{array}$ & $\begin{array}{c}16,64 \mathrm{a} \\
(464,58) \\
\end{array}$ \\
\hline & Mucuna deeringiana & $\begin{array}{c}5,74 \mathrm{a} \\
(0)\end{array}$ & $\begin{array}{c}5,74 \mathrm{a} \\
(0)\end{array}$ & $\begin{array}{l}24,04 \mathrm{~b} \\
(16,40)\end{array}$ & $\begin{array}{c}9,10 \mathrm{~b} \\
(114,49)\end{array}$ & $\begin{array}{c}8,85 \mathrm{~b} \\
(84,62)\end{array}$ \\
\hline & $\mathrm{F}_{\text {Testemunhas }}$ & $\mathrm{ns}$ & $\mathrm{ns}$ & $9,77^{* *}$ & $4,59^{*}$ & $6,58^{* *}$ \\
\hline & $\mathrm{F}_{\text {Testemunhas } x}$ Fatorial $(3 \times 3)$ & $5879,94 * *$ & $343,81^{* *}$ & $22,51 * *$ & $57,70^{* *}$ & $33,75 * *$ \\
\hline & & $10 \mathrm{DAA}$ & \multicolumn{4}{|c|}{$30 \mathrm{DAA}$} \\
\hline \multirow{5}{*}{ Pós-emergência } & Mucuna aterrima & $\begin{array}{c}5,74 \mathrm{a} \\
(0)\end{array}$ & $\begin{array}{c}5,74 \mathrm{a} \\
(0)\end{array}$ & $\begin{array}{l}5,93 \mathrm{a} \\
(35,2)\end{array}$ & $\begin{array}{c}90,00 \mathrm{a} \\
(315,82)\end{array}$ & $\begin{array}{c}36,72 \mathrm{a} \\
(1404,34)\end{array}$ \\
\hline & Mucuna cinerea & $\begin{array}{c}5,74 \mathrm{a} \\
(0)\end{array}$ & $\begin{array}{c}5,74 \mathrm{a} \\
(0)\end{array}$ & $\begin{array}{c}5,76 \mathrm{ab} \\
(33,0)\end{array}$ & $\begin{array}{c}90,00 \mathrm{a} \\
(282,62) \\
\end{array}$ & $\begin{array}{c}33,47 \mathrm{a} \\
(1126,26) \\
\end{array}$ \\
\hline & Mucuna deeringiana & $\begin{array}{c}5,74 \mathrm{a} \\
(0)\end{array}$ & $\begin{array}{c}5,74 \mathrm{a} \\
(0)\end{array}$ & $\begin{array}{l}4,60 \mathrm{~b} \\
(21,2)\end{array}$ & $\begin{array}{l}52,69 \mathrm{~b} \\
(62,56)\end{array}$ & $\begin{array}{c}23,08 \mathrm{~b} \\
(567,67)\end{array}$ \\
\hline & $\mathrm{F}_{\text {Testemunhas }}$ & $\mathrm{ns}$ & $\mathrm{ns}$ & $4,30^{*}$ & $7,30 * *$ & $12,94 * *$ \\
\hline & $\mathrm{F}_{\text {Testemunhas } x}$ Fatorial $(3 \times 3)$ & $2227,35^{* *}$ & $268,69^{* *}$ & $139,37^{*}$ & $40,93^{* *}$ & $264,66^{* *}$ \\
\hline
\end{tabular}

DAA (dias após aplicação); dados entre parênteses correspondem aos valores originais.

Na literatura, verificou-se, em trabalhos com amicarbazone, sulfentrazone e imazapic, controle suficiente até os 120 DAA para Ipomoea nil, I. hederifolia, I. quamoclit, I. grandifolia e Merremia aegyptia (Azania et al., 2009). Entretanto, sulfentrazone e imazapic não apresentaram o mesmo efeito para as espécies de mucuna estudadas, contrapondose ao que foi verificado pelos autores, evidenciando ainda mais a agressividade das espécies de mucuna e a dificuldade em controlá-las. Campos et al. (2009) constataram eficácia de amicarbazone ao controle de I. quamoclit, assim como se verificou, no presente trabalho, eficácia similar à das espécies de $M$. cinerea e $M$. deeringiana.

Quanto às leguminosas, na literatura, os poucos trabalhos encontrados visam ao controle de mucuna-preta. Para Oliveira Neto et al. (2011), o controle químico com as misturas em tanque de glyphosate + 2,4-D + carfentrazone-ethyl e glyphosate $+2,4-\mathrm{D}$ foi a alternativa com maior sucesso no manejo de Mucuna aterrima e Crotalaria spectabilis, viabilizando a sucessão do plantio da canade-açúcar em sistema de cultivo mínimo.
Tabela 2 - Porcentagem de intoxicação obtida pela interação entre os herbicidas sulfentrazone, imazapic e amicarbazone aplicados em pré-emergência e as plantas de Mucuna aterrima, Mucuna cinerea e Mucuna deeringiana, aos 30 e 45 dias após aplicação

\begin{tabular}{|c|c|c|c|c|}
\hline \multirow{2}{*}{ Variável } & \multirow{2}{*}{ Herbicida (A) } & \multicolumn{3}{|c|}{ Espécie (B) } \\
\hline & & MA & $\mathrm{MC}$ & $\mathrm{MD}$ \\
\hline \multirow{3}{*}{ 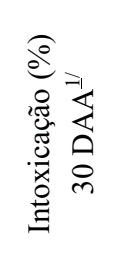 } & sulfentrazone & $\begin{array}{c}41,83 \mathrm{Bb} \\
(44,00)\end{array}$ & $\begin{array}{c}41,83 \mathrm{Bb} \\
(44,00)\end{array}$ & $\begin{array}{c}45,29 \mathrm{Ba} \\
(50,00)\end{array}$ \\
\hline & imazapic & $\begin{array}{c}22,11 \mathrm{Cb} \\
(14,00)\end{array}$ & $\begin{array}{c}18,91 \mathrm{Cc} \\
(10,00)\end{array}$ & $\begin{array}{c}33,52 \mathrm{Ca} \\
(30,00)\end{array}$ \\
\hline & amicarbazone & $\begin{array}{c}57,10 \mathrm{Ab} \\
(70,00)\end{array}$ & $\begin{array}{c}72,05 \mathrm{Aa} \\
(90,00)\end{array}$ & $\begin{array}{c}72,05 \mathrm{Aa} \\
(90,00)\end{array}$ \\
\hline \multirow{3}{*}{ 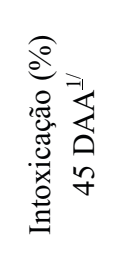 } & sulfentrazone & $\begin{array}{c}56,02 \mathrm{Aa} \\
(68,00)\end{array}$ & $\begin{array}{c}56,21 \mathrm{Ba} \\
(68,00)\end{array}$ & $\begin{array}{c}63,81 \mathrm{Ba} \\
(76,00)\end{array}$ \\
\hline & imazapic & $\begin{array}{c}18,86 \mathrm{Ba} \\
(12,00)\end{array}$ & $\begin{array}{c}11,60 \mathrm{Ca} \\
(6,00)\end{array}$ & $\begin{array}{c}21,21 \mathrm{Ca} \\
(16,00)\end{array}$ \\
\hline & amicarbazone & $\begin{array}{c}64,11 \mathrm{Ab} \\
(80,00)\end{array}$ & $\begin{array}{c}86,41 \mathrm{Aa} \\
(98,00)\end{array}$ & $\begin{array}{c}90,00 \mathrm{Aa} \\
(100,00)\end{array}$ \\
\hline
\end{tabular}

Mucuna aterrima (MA), Mucuna cinerea (MC) e Mucuna deeringiana (MD); letra maiúscula compara-se na coluna e letra minúscula, na linha; dias após aplicação dos herbicidas (DAA);

${ }^{1 /}$ dados transformados em arc sen $(\operatorname{raiz}(x+0,5) / 100)$; dados entre parênteses correspondem aos valores originais. 
A eficácia de mesotrione, aplicado isoladamente e em mistura, foi avaliada por Correia (2011) no controle em pós-emergência de mucunapreta e corda-de-viola em área de cana-soca colhida mecanicamente sem queima da palha, o qual observou que os tratamentos herbicidas proporcionaram $100 \%$ de mortalidade das plantas de mucuna-preta; contudo, nenhum deles apresentou residual de controle no solo para esta espécie. Segundo esse autor, o maior tamanho e o grande acúmulo de reserva das sementes de mucuna-preta podem justificar a ineficácia dos herbicidas no controle em préemergência dessa espécie.

Os sintomas de intoxicação observados na parte aérea das plantas tratadas com amicarbazone, aos 45 DAA, foram caracterizados por necrose das folhas. Nesse caso, o mecanismo de ação do amicarbazone é a inibição da fotossintese das plantas daninhas, causando clorose, redução no crescimento, necrose foliar e eventual morte (Rodrigues \& Almeida, 2011). Para sulfentrazone, os sintomas foram encarquilhamento, manchas necróticas nas folhas e redução de porte, sendo esses sintomas inerentes ao mecanismo de ação do grupo dos inibidores da Protox, pelo qual ocorre um processo de ruptura da membrana celular, provocando rápida dessecação foliar nas plantas que emergem (Rodrigues \& Almeida, 2011). No caso do imazapic, pertencente aos herbicidas inibidores da enzima ALS, foi observada apenas a redução no porte das plantas. No entanto, Rodrigues \& Almeida (2011) comentaram que, embora a interrupção do crescimento e a morte das regiões meristemáticas das plantas possam ocorrer logo após a aplicação, a clorose das folhas mais novas e a necrose dos tecidos podem demorar até quatro semanas.
A intensidade dos sintomas de intoxicação na parte aérea das plantas também pode estar relacionada com as características fisico-químicas e a dinâmica do herbicida no solo e na planta, possivelmente favorecida pela umidade no solo proporcionada pelos $1.118,3 \mathrm{~mm}$ de chuvas do período (Tabela 3). O amicarbazone possui $4.600 \mathrm{ppm}$ para solubilidade e lipofilicidade, com Kow entre 15 e 17 (Gimenes, 2004), sendo os maiores valores em relação aos demais herbicidas utilizados. No solo, a umidade pode ter favorecido a disponibilização do herbicida na solução do solo, e a lipofilicidade, colaborado com a penetração do herbicida no interior das plantas, refletindo nos sintomas de intoxicação mais intensos.

Os herbicidas, além das injúrias observadas na parte aérea, também reduziram o comprimento das plantas, o número e o acúmulo de massa seca das espécies estudadas. Para todas as variáveis, as plantas tratadas com amicarbazone foram as mais afetadas, enquanto as plantas do tratamento com sulfentrazone foram intermediárias e, com imazapic, menos prejudicadas. $M$. deeringiana foi a espécie que apresentou os maiores prejuizos às variáveis avaliadas, seguida por $M$. aterrima e $M$. cinerea (Tabela 4).

As plantas de $M$. deeringiana apresentaram-se em menor número, além do comprometimento no comprimento da planta e acúmulo de massa seca quando tratadas com amicarbazone e sulfentrazone, mas pouco prejuízo com imazapic. $M$. aterrima, que é a espécie mais preocupante para os produtores de canade-açúcar, dada sua frequência, e $M$. cinerea foram as mais sensiveis ao amicarbazone, com acúmulos de massa seca de 7,96 e $1,06 \mathrm{~g}$ por planta aos 45 DAA, respectivamente (Tabela 4).

Tabela 3 - Temperatura média e precipitação observadas durante o período experimental e média histórica dos últimos 19 anos

\begin{tabular}{|c|c|c|c|c|c|}
\hline & \multirow{3}{*}{ Mês } & \multirow{2}{*}{\multicolumn{2}{|c|}{ Temperatura Média }} & \multirow{2}{*}{\multicolumn{2}{|c|}{$\begin{array}{c}\text { Precipitação Mensal } \\
(\mathrm{mm})\end{array}$}} \\
\hline & & & & & \\
\hline & & Experimento & Média histórica $^{\underline{1}}$ & Experimento & Média histórica $^{1}$ \\
\hline \multirow{3}{*}{ ஓें } & Outubro & 22,0 & 23,2 & 65,6 & 120,0 \\
\hline & Novembro* & 24,7 & 23,6 & 267,7 & 156,1 \\
\hline & Dezembro & 22,7 & 24,2 & 398,8 & 224,5 \\
\hline \multirow{2}{*}{$\stackrel{\circ}{\circ}$} & Janeiro & 22,8 & 24,4 & 322,1 & 274,0 \\
\hline & Fevereiro & 24,5 & 24,6 & 64,1 & 207,5 \\
\hline
\end{tabular}

Fonte: IAC/CIIAGRO, ${ }^{1 /}$ últimos 19 anos. ${ }^{*}$ mês da aplicação em pré e pós-emergência. 
Tabela 4 - Número de plantas, comprimento e massa seca da parte aérea obtidos pela interação entre os herbicidas sulfentrazone, imazapic e amicarbazone aplicados em préemergência e as espécies de Mucuna aterrima, Mucuna cinerea e Mucuna deeringiana, aos 45 dias após aplicação

\begin{tabular}{|c|c|c|c|c|}
\hline \multirow{2}{*}{ Variável } & \multirow{2}{*}{ Herbicida (A) } & \multicolumn{3}{|c|}{ Espécie (B) } \\
\hline & & MA & $\mathrm{MC}$ & MD \\
\hline \multirow{3}{*}{ 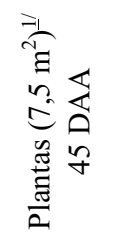 } & sulfentrazone & $\begin{array}{l}5,60 \mathrm{Ba} \\
(31,40)\end{array}$ & $\begin{array}{l}6,40 \mathrm{Aa} \\
(40,20)\end{array}$ & $\begin{array}{c}3,05 \mathrm{Ab} \\
(8,60)\end{array}$ \\
\hline & imazapic & $\begin{array}{c}6,70 \mathrm{Aa} \\
(44,20)\end{array}$ & $\begin{array}{c}6,75 \mathrm{Aa} \\
(44,80)\end{array}$ & $\begin{array}{c}3,87 \mathrm{Ab} \\
(15,40)\end{array}$ \\
\hline & amicarbazone & $\begin{array}{c}2,93 \mathrm{Ca} \\
(6,00)\end{array}$ & $\begin{array}{c}1,39 \mathrm{Bb} \\
(1,00)\end{array}$ & $\begin{array}{c}1,00 \mathrm{Bb} \\
(0,00)\end{array}$ \\
\hline \multirow{3}{*}{ 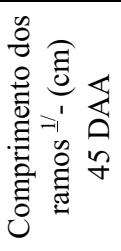 } & sulfentrazone & $\begin{array}{l}5,81 \mathrm{Ba} \\
(32,80)\end{array}$ & $\begin{array}{l}5,82 \mathrm{Ba} \\
(34,92)\end{array}$ & $\begin{array}{c}3,79 \mathrm{Ab} \\
(13,73)\end{array}$ \\
\hline & imazapic & $\begin{array}{c}9,17 \mathrm{Ab} \\
(84,42)\end{array}$ & $\begin{array}{l}11,17 \mathrm{Aa} \\
(125,44)\end{array}$ & $\begin{array}{l}5,21 \mathrm{Ac} \\
(26,49)\end{array}$ \\
\hline & amicarbazone & $\begin{array}{l}5,70 \mathrm{Ba} \\
(31,95)\end{array}$ & $\begin{array}{l}4,07 \mathrm{Ba} \\
(18,20)\end{array}$ & $\begin{array}{c}1,00 \mathrm{Bb} \\
(0,00)\end{array}$ \\
\hline \multirow{3}{*}{ 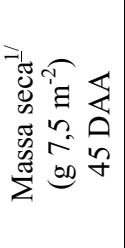 } & sulfentrazone & $\begin{array}{l}5,98 \mathrm{Aa} \\
(35,93)\end{array}$ & $\begin{array}{l}8,05 \mathrm{Ba} \\
(72,72)\end{array}$ & $\begin{array}{c}2,59 \mathrm{Bb} \\
(6,34)\end{array}$ \\
\hline & imazapic & $\begin{array}{l}16,68 \mathrm{Ab} \\
(280,77)\end{array}$ & $\begin{array}{c}20,48 \mathrm{Aa} \\
(433,82)\end{array}$ & $\begin{array}{l}5,90 \mathrm{Ac} \\
(38,14)\end{array}$ \\
\hline & amicarbazone & $\begin{array}{c}2,95 \mathrm{Ba} \\
(7,96)\end{array}$ & $\begin{array}{c}1,41 \mathrm{Ca} \\
(1,06)\end{array}$ & $\begin{array}{c}1,00 \mathrm{Ba} \\
(0,00)\end{array}$ \\
\hline
\end{tabular}

Mucuna aterrima (MA), Mucuna cinerea (MC) e Mucuna deeringiana (MD); ${ }^{1 /}$ dados transformados em raiz $(\mathrm{x}+0,5)$; dias após aplicação dos herbicidas (DAA); letra maiúscula compara-se na coluna e letra minúscula, na linha; dados entre parênteses correspondem aos valores originais.

Na pós-emergência, o clomazone propiciou os efeitos menos severos de injúrias (10\%) aos 10 DAA, enquanto na aplicação de ametryn+ trifloxysulfuron-sodium e 2,4-D os efeitos foram mais acentuados, representados por 80 a $90 \%$ e 82 a $92 \%$, respectivamente, de acordo com a Tabela 5. Nas folhas, a injúria proporcionada pelos herbicidas foi observada desde os 5 DAA, sendo caracterizada por branqueamento nas folhas das plantas tratadas com clomazone, murchamento naquelas tratadas com 2,4-D e necrose das folhas tratadas com ametryn+trifloxysulfuron-sodium.

Para as espécies de mucuna, os resultados justificam a não aplicação do herbicida clomazone, que propiciou apenas ligeira descoloração e menor porte das plantas (Tabela 5). A não eficácia do clomazone em pós-emergência ficou evidenciada e também foi constatada por Raimondi et al. (2010) nas espécies de Amaranthus hybridus, A. lividus e A. spinosus até 30 DAA.

Aos 15 DAA, a intoxicação aumentou com a aplicação em pós-emergência do clomazone (de 10 para $38,67 \%$ ) e $M$. aterrima foi a espécie com menos injúrias. Entretanto, por ocasião da última avaliação, aos 30 DAA, o clomazone ainda diferia dos demais herbicidas, com redução de valor em comparação aos 15 DAA; contudo, para ametryn+trifloxysulfuronsodium e 2,4-D os valores mantiveram-se superiores a $90 \%$ e com efeitos severos (dados não apresentados).

O tratamento com clomazone por ter sido o que menos causou intoxicação; também foi o que menos interferiu no comprimento das plantas aos 30 DAA, seguido pelo ametryn+trifloxysulfuron-sodium (Tabela 5). $M$. deeringiana teve o comprimento mais reduzido do que o das demais, porém trata-se de uma espécie anã, com hábito de crescimento determinado, com ciclo curto e menor produção de massa vegetal em relação às demais espécies de Mucuna.

Aos 30 DAA, as plantas de Mucuna foram mais afetadas pelo ametryn+trifloxysulfuronsodium e 2,4-D, enquanto o clomazone praticamente não alterou o número de plantas de $M$. aterrima e $M$. cinerea (Tabela 5). Na literatura, resultados similares foram encontrados para ametryn+trifloxysulfuron-sodium em outras espécies de plantas daninhas. Por exemplo, Correia \& Kronka Jr. (2010) observaram controle de $60 \%$ para $M$. aegyptia, e Oliveira \& Freitas (2009), controle eficiente de Rottboelia exaltata-ambas as espécies tidas como agressivas e de dificil controle.

Os herbicidas específicos para pós-emergência, a exemplo do 2,4-D e ametryn+ trifloxysulfuron-sodium, possuem residual curto no solo (Rodrigues \& Almeida, 2011) e, consequentemente, maior dificuldade em conter novos fluxos de emergência de plantas. Essa questão, associada à dormência das mucunas, particularmente de $M$. aterrima, e a capacidade de emitir diferentes fluxos de emergência, independentemente do sombreamento do solo pelas culturas, podem ser indicativo de que herbicidas em pós-emergência possam controlar as infestações apenas durante determinado período. Em áreas 
Tabela 5 - Porcentagem de intoxicação observada aos 10 DAA, número de plantas e massa seca aos 30 DAA, obtida pela interação entre os herbicidas clomazone, ametryn+trifloxysulfuron e 2,4-D aplicados em pós-emergência sobre as espécies de Mucuna aterrima, Mucuna cinerea e Mucuna deeringiana

\begin{tabular}{|c|c|c|c|c|}
\hline \multirow{2}{*}{ Variável } & \multirow{2}{*}{ Herbicida (A) } & \multicolumn{3}{|c|}{ Espécie (B) } \\
\hline & & MA & $\mathrm{MC}$ & MD \\
\hline \multirow{3}{*}{$\begin{array}{c}\text { Intoxicação }^{1 / /}(\%) \\
10 \text { DAA }\end{array}$} & clomazone & $\begin{array}{c}18,91 \mathrm{Ba} \\
(10,00)\end{array}$ & $\begin{array}{c}18,91 \mathrm{Ca} \\
(10,00)\end{array}$ & $\begin{array}{c}18,91 \mathrm{Ca} \\
(10,00)\end{array}$ \\
\hline & ametryn+trifloxysulfuron-sodium & $\begin{array}{c}70,40 \mathrm{Aa} \\
(88,00)\end{array}$ & $\begin{array}{c}72,05 \mathrm{Aa} \\
(90,00)\end{array}$ & $\begin{array}{c}64,11 \mathrm{Bb} \\
(80,00)\end{array}$ \\
\hline & $2,4-\mathrm{D}$ & $\begin{array}{c}70,40 \mathrm{Aab} \\
(88,00)\end{array}$ & $\begin{array}{c}65,44 \mathrm{Bb} \\
(82,00)\end{array}$ & $\begin{array}{c}75,64 \mathrm{Aa} \\
(92,00)\end{array}$ \\
\hline \multirow{3}{*}{$\begin{array}{c}\text { Número de plantas } \\
\text { 30 DAA }\end{array}$} & clomazone & $\begin{array}{l}5,48 \mathrm{Aa} \\
(30,00)\end{array}$ & $\begin{array}{l}5,73 \mathrm{Aa} \\
(32,60) \\
\end{array}$ & $\begin{array}{c}2,80 \mathrm{Ab} \\
(9,40)\end{array}$ \\
\hline & ametryn+trifloxysulfuron-sodium & $\begin{array}{c}2,86 \mathrm{Ba} \\
(8,20)\end{array}$ & $\begin{array}{c}1,16 \mathrm{Bb} \\
(1,20)\end{array}$ & $\begin{array}{c}1,94 \mathrm{Aab} \\
(3,40)\end{array}$ \\
\hline & 2,4-D & $\begin{array}{c}2,60 \mathrm{Ba} \\
(6,60)\end{array}$ & $\begin{array}{c}0,81 \mathrm{Bb} \\
(0,20)\end{array}$ & $\begin{array}{c}0,71 \mathrm{Bb} \\
(0,00)\end{array}$ \\
\hline \multirow{3}{*}{$\begin{array}{c}\text { Massa seca }{ }^{2 /} \\
\left(\mathrm{g} 7,5 \mathrm{~m}^{-2}\right) \\
30 \mathrm{DAA}\end{array}$} & clomazone & $\begin{array}{l}29,06 \mathrm{Ab} \\
(869,10) \\
\end{array}$ & $\begin{array}{l}34,85 \mathrm{Aa} \\
(1223,43) \\
\end{array}$ & $\begin{array}{l}9,91 \mathrm{Ac} \\
(133,88) \\
\end{array}$ \\
\hline & ametryn+trifloxysulfuron-sodium & $\begin{array}{l}3,47 \mathrm{Ba} \\
(12,54)\end{array}$ & $\begin{array}{c}1,53 \mathrm{Ba} \\
(1,85)\end{array}$ & $\begin{array}{c}2,82 \mathrm{Ba} \\
(9,04)\end{array}$ \\
\hline & 2,4-D & $\begin{array}{c}3,78 \mathrm{Ba} \\
(13,74)\end{array}$ & $\begin{array}{c}1,00 \mathrm{Ba} \\
(1,22)\end{array}$ & $\begin{array}{c}1,00 \mathrm{Ba} \\
(0,00)\end{array}$ \\
\hline
\end{tabular}

Mucuna aterrima (MA), Mucuna cinerea (MC) e Mucuna deeringiana (MD); Letra maiúscula compara-se na coluna e letra minúscula, na linha, ${ }^{1 /}$ dados transformados em arc sen $(\operatorname{raiz}(x+0,5) / 100) ;{ }^{2 / d a d o s}$ transformados em raiz $(x+0,5)$; dados entre parênteses correspondem aos valores originais.

intensamente infestadas por mucunas, certamente seria necessário realizar mais de uma aplicação em pós-emergência.

A massa seca aos 30 DAA apresentou diferenças devido às poucas injúrias ocasionadas pelo clomazone (dado não apresentado), que resultaram em maior número de plantas e, consequentemente, acúmulo de massa seca (Tabela 5). Entre as espécies, M. aterrima e $M$. cinerea tiveram o maior acúmulo de massa seca, enquanto $M$. deeringiana diferiu, com menor valor, por ser uma espécie anã. O desdobramento da interação ocorrida para esta variável evidenciou que as espécies menos tolerantes foram Mucuna deeringiana para o herbicida 2,4-D e $M$. cinerea para 2,4-D e ametryn+trifloxysulfuron-sodium. A aplicação de ametryn+trifloxysulfuron-sodium ou de 2,4-D proporcionou sintomas de intoxicação intensos na parte aérea das plantas, sugerindo uma possivel recomendação desses herbicidas em pós-emergência.

Assim, considerando o comportamento de hábitos de desenvolvimento diferenciados entre as espécies de Mucuna, os resultados indicaram que em aplicação em pré-emergência as espécies estudadas foram sensiveis ao amicarbazone, seguido de sulfentrazone, e tolerantes ao imazapic; em pós-emergência, foram sensiveis ao ametryn+trifloxysulfuronsodium e 2,4-D, mas tolerantes ao clomazone.

\section{LITERATURA CITADA}

AZANIA, C. A. M. et al. Manejo químico de Convolvulaceae e Euphorbiaceae em cana-de-açúcar em período de estiagem. Planta Daninha, v. 27, n. 4, p. 841-848, 2009.

CAMPOS, L. H. F. et al. Suscetibilidade de Ipomoea quamoclit, I. triloba e Merremia cissoides aos herbicidas sulfentrazone e amicarbazone. Planta Daninha, v. 27, n. 4, p. $831-840,2009$.

CORREIA, N. M. Eficácia do mesotrione aplicado isolado e em mistura para o controle de corda-de-viola e de mucuna preta em cana-soca. Álcoolbras, n. 133, p. 46-51, 2011.

CORREIA, N. M.; KRONKA JR., B. Controle químico de plantas dos gêneros Ipomoea e Merremia em cana-soca. Planta Daninha, v. 28, n. 4, p. 1143-1152, 2010 
FAVERO, C. et al. Modificações na população de plantas espontâneas na presença de adubos verdes. Pesq. Agropec. Bras., v. 36, n. 11, p. 1355-1362, 2001

FERNANDES, M. F.; BARRETO, A. C.; EMÍDIO FILHO, J. Fitomassa de adubos verdes e controle de plantas daninhas em diferentes densidades populacionais de leguminosas. Pesq. Agropec. Bras., v. 34, n. 9, p. 1593-1600, 1999.

GIMENES, R. Dinamic: o novo herbicida da Hokko do Brasil para cana-de-açúcar. STAB, v. 22, n. 4, p. 23-24, 2004.

DUARTE JÚNIOR, J. B..; COELHO, F. C. A cana-de-açúcar em sistema de plantio direto comparado ao sistema convencional com e sem adubação. R. Bras. Eng. Agríc. Amb., v. 12, n. 6, p. 576-583, 2008.

MAEDA, J. A.; LAGO, A. A. Germinação de sementes de mucuna-preta após tratamentos para superação da impermeabilidade do tegumento. R. Bras. Sementes, v. 8, n. 1, p. 79-84, 1986

OLIVEIRA NETO, A. M. et al. Manejo químico de adubos verdes para sucessão da cana-de-açúcar em sistema de cultivo mínimo. R. Bras. Herbic., v. 10, n. 2, p. 86-94, 2011.

OLIVEIRA, A. R.; FREITAS, S. P. Palha de cana-de-açúcar e herbicidas no controle de Rottboellia exaltata. Bragantia, v. 68 , n. 1, p. 187-194, 2009.
RAIMONDI, M. A. et al. Atividade residual de herbicidas aplicados ao solo em relação ao controle de quatro espécies de Amaranthus. Planta Daninha, v. 28, n. 4, p. 1073-1085, 2010 .

RODRIGUES, B. N.; ALMEIDA, F. S. In: Guia de herbicidas. 6.ed. Londrina: 2011. 697 p.

SAKAI, R. H. et al. Avaliação agronômica de quatro espécies de mucuna utilizadas como adubos verdes em sistema agroecológico. R. Bras. Agroecol., v. 2, n. 1, p. 910-913, 2007.

SOUZA, M. F. P.; YAMASHTTA, O. M. Potencial alelopático da mucuna-preta sobre a germinação de sementes de alface e picão preto. R. Ci. Agro-Amb., v. 4, n. 1, p. 23-28, 2006.

TRANI, P. E.; BULISANI, E. A.; BRAGA, N. R. Adubação verde. Campinas: Coordenadoria de Assistência Técnica Integral - CATI, 1991. 13 p. (Boletim Técnico, 197)

WUTKE, E. B.; MAEDA, J. A.; PIO, R. M. Superação da dormência de sementes de mucuna-preta pela utilização de "calor seco". Sci. Agríc., v. 52, n. 3, p. 482-490, 1995. 